\title{
Can majority support save an endangered language? A case study of language attitudes in Guernsey
}

\author{
Julia Sallabank $^{* 1}$
}

Endangered Languages Academic Programme, SOAS, University of London, UK

\begin{abstract}
Many studies of minority language revitalisation focus on the attitudes and perceptions of minorities, but not on those of majority group members. This paper discusses the implications of this, and presents research into majority and minority attitudes towards the endangered indigenous vernacular of Guernsey, Channel Islands. The research uses a multi-method approach (questionnaire and interview) to obtain attitudinal data from a representative sample of the population that includes politicians and civil servants (209 participants). The findings suggest a shift in language ideology away from the postsecond world war 'culture of modernisation' and a monolingual ideal, toward recognition of the value of a bilingual or trilingual linguistic heritage. Public rhetoric in Guernsey now seems to support the maintenance of the indigenous language, which has resulted in a degree of official support. The paper then discusses to what extent this 'attitude shift' is reflected in linguistic behaviour and in concrete language planning measures.
\end{abstract}

Keywords: language attitudes; diglossia; covert attitudes; language policy; revitalisation

\section{Introduction}

Most sociolinguistic studies of minority languages focus on the attitudes of their speakers and the relationship of these attitudes to ethnolinguistic vitality and language maintenance (e.g., Currie and Hogg 1994; Dorian 1981; Jones 2001; Priestly 1989; Williamson 1991; to name

\footnotetext{
*Email: js72@soas.ac.uk
} 
but a few). But given that they belong to the minority, speakers' attitudes do not necessarily carry weight with decision-makers. Language revitalisation movements which have been presented as the most successful generally started as grass-roots campaigns, which eventually lobbied for official support and funding, e.g. Māori in New Zealand, or Welsh in Wales (see Edwards and Newcombe 2005; Grenoble and Whaley 2006; Spolsky 2004). This implies at least passive acceptance by the majority community, whose financial support is needed to fund official language planning measures.

A few studies do look at majority attitudes (e.g. Annamalai 2004; Baker 1992; Edwards 1977; Garrett, Coupland and Williams 2003; Hoare and Coveney 2000), but tend to find negative attitudes (May 2006). The Māori case is a rare example where a government has taken active steps to promote a minority indigenous language to the majority population, albeit with mixed results (De Bres 2011). It follows that more research is necessary into: (a) whether and how predominantly negative language attitudes and ideologies among both majority and minority group members can change, and (b) whether, if there is majoritypopulation support for minority language maintenance, the effectiveness of language planning is increased. This paper discusses these issues as illustrated by research into attitudes towards Guernesiais, the endangered indigenous vernacular of Guernsey, Channel Islands.

\section{Background to the study}

Guernsey is the second largest of the Channel Islands, which are situated in the English Channel off Normandy and Brittany. Politically, the islands are self-governing dependencies of the English Crown, a situation they have held since the incorporation of mainland Normandy into the kingdom of France in 1204. They are not members of the United 
Kingdom or European Union, and staunchly guard their independence. Each main island has its own indigenous Norman language, but these have not traditionally been viewed as linked to political independence (although there are indications that the island governments may increasingly be utilising language as a token of distinctiveness).

In the 2001 census results (States of Guernsey 2002), just over $2 \%$ of the population (1,327 people) reported speaking Guernesiais fluently, although 14\% said they understood some. However, two-thirds of the fluent speakers were aged over 64 in 2001, and although the census planned for 2011 has been postponed indefinitely, it is clear that the number of fluent speakers (and the overall level of fluency) has fallen considerably since 2001, perhaps to as low as a couple of hundred. Most of the fluent speakers are aged 80 or over; there are very few speakers below the age of 60 .

\section{Traditional attitudes toward Guernesiais}

For several hundred years, from at least the sixteenth to the late nineteenth century, Guernesiais was in a classic diglossic relationship with (standard) French (as defined by Ferguson 1959). French was used for high-status domains such as government, the judiciary, religion, and education. Guernesiais was used in domestic domains, for private purposes and phatic communication, and was associated with the social identity of speakers. This may be seen as a classic dichotomy between solidarity and status values in social-psychological terms, although in contrast to Ryan (1979), solidarity values have not been strong enough to prevent language shift. French was used as the standardised written form, while Guernesiais had (and still has) wide variations in pronunciation, grammar and lexis, and no settled orthography. This led to internalisation by speakers of inferiority in relation to French, which continues to affect language attitudes today (see below). As observed by Jaffe $(1999,41)$ with 
regard to Corsica, '[d]iglossia described the hierarchical, oppositional relationship between Corsican and French. It indexed language practices (specifically, the exclusion of Corsican from the powerful public sphere) as well as language attitudes. These were intimately connected'.

As with many other minority vernaculars, until the last 30 years or so Guernesiais was perceived as an impediment to social advancement. Especially after the Second World War, the traditional language and culture were associated with backwardness and poverty; English was seen as the route to economic advantage.

One of the commonly expressed attitudes towards Guernesiais is that it is "not a proper language' but either a dialect of French or a mixture of English and French. The term patois is often used to refer to Guernesiais. In French this has connotations of 'incorrect, corrupt', while in English it can refer to a creole, as in Jamaican Patois. Older speakers still often refer to Guernesiais as frënçais /frẽse/ ('French') and to French as lé buon frënçais (or in English as 'the good French'). This might indicate that they see French and Guernesiais as points on a continuum, with a lack of (mental) distance between the two. This is compounded by the connotations of patois in French of nonstandard, deviant, and incorrect compared to French, the language of civilisation (Métivier 1866), which inevitably led to a perception of Guernesiais as deficient. Spence $(1993,4)$ describes the effects of such attitudes on the neighbouring island of Jersey as follows:

The fact that many of those who habitually spoke Jèrriais themselves regarded it as a "patois" is certainly a significant factor in its decline, in so far as it made them less committed to the survival of the vernacular, and influenced the attitude of their children.

Some modern-day supporters of Guernesiais, on the other hand, maintain that Guernesiais should be seen as a variety of Norman, a branch of the oil family of northern 
France with a prestigious history (e.g., Gallienne 2004). Reclaiming prestige is an important principle: Price $(1984,208)$ asserts that ' $[\mathrm{t}]$ hese are ... varieties of Norman French and the idea that they are a "corruption" of standard French is devoid of all foundation.' One of my questionnaire respondents (AQ23) wrote:

When I was at school (1960s), it was the perception that Guernsey French was an inferior language, a language of peasants! One was looked down upon as being "countrified" if one was associated with the language. There seemed to be no comprehension, or if there was, no acceptance, that Norman French was the language of William the Conqueror, that it preceded French, that it is our heritage! As such, I feel strongly that it should not be allowed to disappear. ... I believe there has to be a greater effort yet to promote the language at the political level, at this eleventh hour so as to try to ensure that our own heritage is preserved.

Although no comparable surveys were carried out in the mid-twentieth century, respondents consistently report that attitudes then were much more negative than they are now. Respondent GF38 recounted that his aunt used to rebuke his mother for speaking to his sister in Guernesiais, because she would 'never know English'. Respondent GF39's mother 'took a lot of stick' for allowing her to speak Guernesiais:

It was because - I think it was early ' $50 \mathrm{~s}$, the war was over and so on and it wasn't fashionable at the time ... a lot of the other mothers [said] "oh gosh you know you're letting her speak patois and when she goes to school she won't be able to learn - she'll be a dunce" and all the rest of it. 
Another interviewee (GF25) reported that when his brother started school in the $1950 \mathrm{~s}$, he was told to 'go home and come back when you can speak English'.

A small survey carried out for an MA dissertation in the 1990s (Domaille 1996) indicates that at that time the ethnolinguistic vitality of Guernesiais was declining in terms of speaker numbers, visibility/audibility in the public sphere, and attitudes.

Nevertheless, in the early twenty-first century it became increasingly evident from interviews, anecdotal reports, and the media that attitudes towards Guernesiais were becoming increasingly positive. According to my interviewees:

... aoshtaeirr i voudrei tou lé dvisaï - mais ya lei droine vingt ae shétei 'you come from the country you' et yera aen pti - mei aoshtaeirr lei jonne gens veule tou lé faire. (GF11) [now they'd all like to speak it - but twenty years ago it was 'you come from the country you' and there'll be a bit - but now the young people all want to do it.]

Nowadays you're the 'cat's whiskers' if you speak Guernsey French. (GE4)

I think that was the thing - that's how we started to lose it after the war er it wasn't the in thing - to speak Guernsey French and that is right that in certain company you didn't speak it - because it made you feel a bit inferior but now it's the other way round - you don't feel at all inferior if you know it, it's completely the opposite you know?

To test these anecdotal reports of 'attitude shift' (a term introduced by Dorian 1993), a questionnaire survey was carried out in 2004, including attitude statements measured on a Likert scale, demographic factors, and identity-related issues. This survey aimed specifically at eliciting the attitudes of Anglophones, the majority community in Guernsey. The year 2004 was an opportune time to conduct such research, as: (1) it was the 800th anniversary of 
independence and this focused attention on island identity; and (2) the profile of Guernesiais had been raised by the introduction of voluntary extra-curricular classes at three primary schools.

\section{Sampling, distribution and representativeness}

The survey was carried out in the form of a questionnaire partly in order to include a wider range of respondents than could be interviewed in the time available, and partly because quantitative data is more highly valued by decision-makers than qualitative ethnographic data. Results were incorporated into a report commissioned by the States of Guernsey Culture and Leisure Ministry in 2007. Follow-up interviews were carried out with $10 \%$ of respondents, and politicians and civil servants were also interviewed.

It was felt to be important that the selection of informants should be as representative as possible of the population as a whole. Large-scale surveys sometimes use random, house-tohouse sampling, as suggested by Williamson (1991). However, such 'random' surveys can never be truly representative unless they take into account the sociolinguistic profiles of different neighbourhoods. Given the general trend for endangered languages to decline in urban areas first, there is no evidence to doubt 'folk linguistic' reports that people who are proficient in Guernesiais are more likely to live in rural areas. (Unfortunately the 2001 Guernsey census report does not provide correlations by language proficiency and area, although this information was collected.) Youngman (1978) favours identifying respondents individually over chance or random mailings, as those who answer mailings or internet surveys will be self-selected and may be unrepresentative, especially in an attitude survey. For my survey informants were contacted via the 'friend of a friend' method (Milroy 1987), where the researcher makes contact with a core of people who then provide contact with 
others. A range of contacts were asked to find other respondents who were not committed language revitalisation enthusiasts, but preferably people who had not thought much about language issues (many of them contacted through workplaces). The core contacts exerted pressure to return the questionnaire, leading to a high level of response.

A total of 209 questionnaires were returned $(0.35 \%$ of the 59,710 population counted in the 2001 census). The demographic profile of respondents matched the census in that only $2.26 \%$ reported speaking Guernesiais fluently (compared to $2.22 \%$ in the census ${ }^{2}$ ), and one third were non-Guernsey-born. In the census, $51.4 \%$ of the population was female and $48.6 \%$ male, whereas in the survey a slightly higher proportion of those who indicated their gender was female (58.8\%). Questions on level of education and occupation were included to try to gauge respondents' socioeconomic status. The 2001 census tallied qualifications in a cumulative manner, using two methods of counting, which was deemed to be confusing. It would appear, however, that the sample was on balance more highly qualified than the general population. Respondents with no qualifications tended to express less positive attitudes towards Guernesiais, while those with postgraduate qualifications tended towards positive statements, although the difference is not statistically significant.

The data were cross-tabulated using SPSS, which helped to relate major structural and individual variables to attitudes towards Guernesiais. As some participants changed their responses in follow-up interviews, I was cautious about using more detailed statistical analysis. Instead, results were triangulated through qualitative interviews with $10 \%$ of survey respondents. 


\section{Overt and covert attitudes}

Attitude statements are just that: overt statements. It is commonly found that people will overtly express one kind of attitude and then behave in a way which is inconsistent with it (Fishbein and Ajzen 1975, cited in Potter and Wetherell 1987, 53). In surveys such as the one described here, which rely on self-reports, respondents may consciously or unconsciously disguise inner attitudes (Baker 1992). Respondents may try to project attitudes they feel are more socially acceptable or which they presume the researcher is looking for (Low 1999). Dauenhauer and Dauenhauer (1998) suggest that private (covert) attitudes may be seen as more closely reflecting underlying ideologies than overt (public) statements, and may thus be more likely to be reflected in behaviour, which in turn affects the outcome of language planning measures.

For this reason, interviews and ethnographic observations were used to supplement the attitudes questionnaire, both for triangulation and to compare overtly expressed attitudes with behaviour. Difficulties inherent in trying to obtain a 'true' picture of attitudes are illustrated by the fact that in follow-up interviews some questionnaire respondents gave different answers to their survey ones.

\section{Results}

When the questionnaire results were analysed, the overall strength of support expressed for Guernesiais was higher than anticipated, even given the previous anecdotal reports. The same distribution is seen across the variables of gender, job sector, and geographical origin, as well as proficiency in Guernesiais (see Figure 1). The statements 'It doesn't matter if Guernsey Norman French ${ }^{3}$ dies out' and 'Guernsey Norman French is irrelevant to the modern world' 
were found to illustrate the results the most clearly $(50.5 \%$ disagreed strongly and $25.3 \%$ mildly with the former).

\section{[FIG 1 NEAR HERE]}

When the results were analysed by age group, under-18s were found to be marginally more likely to have negative attitudes, but this was not statistically significant. Nevertheless, as the number of young people learning a language is seen as emblematic of its vitality, the attitudes of young people were investigated in more detail and are discussed below.

Overall, higher levels of educational achievement were associated with more positive attitudes towards Guernesiais, but again not to a statistically significant degree. The occupations most favourable towards measures to support the indigenous language were healthcare, education, and IT, with the financial sector and civil service more evenly divided. The effectiveness of school-based language policies may be impacted by the finding that students were the least favourably disposed; once again, however, the difference was not statistically significant (Pearson $r=0.782$ ). Further cross-tabulation established that educators are the profession most likely to come from outside the island, yet also tend to be pro-Guernesiais, whereas the students questioned were all Guernsey-born.

Questionnaire responses, comments and interviews all indicated concern for the loss of island distinctiveness. We found that $70 \%$ of respondents 'agreed strongly' with the statement 'Guernsey should maintain a unique identity of its own', with 25\% more agreeing mildly (remembering that only $67 \%$ of respondents were born in Guernsey). Only $0.5 \%$ disagreed strongly with this statement. Only five respondents disagreed at all. Students were proportionately less likely to agree strongly, although none disagreed and, once again, the difference is not statistically significant. Comments included: 
We must maintain our independent culture and heritage. (AQ27)

Very sad to see Anglicization [of] many aspects of Guernsey life. (AQ70)

Guernsey is a unique island and needs to be kept that way. Our language is important in identifying Guernsey people. (AQ113)

Guernsey French identifies the island even though I don't speak it ... necessary to keep it going to keep island identity. (AQ88)

Despite the stated attachment to cultural heritage, responses to the statement 'Speaking Guernsey Norman French is an important part of Guernsey identity' were relatively equivocal, with only $24.7 \%$ of those who answered this question agreeing strongly, $34.3 \%$ agreeing mildly, and $25.3 \%$ neutral. Nevertheless, only $8.6 \%$ disagreed strongly and $7.1 \%$ disagreed mildly with this statement.

Likewise, while an overwhelming majority agreed with the statement 'Guernsey Norman French is an important part of our heritage', the distribution of responses to the statement 'Guernsey Norman French is irrelevant to the modern world' was more even. This may indicate that while Guernesiais is valued for symbolic identity and island distinctiveness, it is associated with nostalgia and traditional culture rather than being seen as a living form of communication. In addition, island identity might be expressed more through symbolic attachment to language-as-heritage than to actual linguistic behaviour. As discussed below, subsequent ethnographic study confirmed these hypotheses, which have important implications for language planning. 
Backing for general government language support was considerably higher than the proportion who felt that Guernesiais should be taught in schools: $62.2 \%$ of men and $67.2 \%$ of women agreed either strongly or mildly with the statement 'Guernsey Norman French should be taught in schools' (standard deviation: 1.379). There were no statistically significant effects for gender, origin, or proficiency in Guernesiais.

Although teaching Guernesiais in schools (in optional extra-curricular lessons) is the mostly widely publicised and longest-running language-related activity - and the one that interviewees associated most strongly with 'saving Guernesiais' - these responses suggest that language planning might benefit from focusing on other areas than formal education. In interviews and written comments some respondents mentioned the already crowded curriculum, while some stressed that lessons should be voluntary. Some felt that teaching a major world language would be more useful, while others questioned the efficacy of extracurricular lessons. One suggested that association with school could put children off Guernesiais; in Ireland, 'compulsory Irish' has had such an effect (Fennell 1981; Cooper 1989).

The vast majority of respondents expressed disagreement with the statements 'Guernsey Norman-French is just corrupt French' and 'You can't speak English properly if you speak Guernsey Norman-French', which were included because such attitudes had been cited by previous interviewees as reasons for language shift. Such views are no longer seen as acceptable in overt statements: only four respondents agreed strongly and six mildly with the former, and just one strongly and two mildly with the latter. However, subsequent research has found that some islanders still covertly perceive Guernesiais as inferior to French (see below). 
Overall, only $16 \%$ of respondents disagreed with the statement 'I would like to know Guernsey Norman-French'. To avoid complications regarding attitudes and behaviour, the statement deliberately did not imply any action. Written comments included:

I wish I could speak but I'm a very lazy learner. (AQ87)

Regrettably I am one of the worst type of hypocrites! I wish the language to remain a part of the island's culture but find excuses not to do something about it myself. (AQ187)

Self-reported attitudes towards Guernesiais thus seem to be generally positive across the population as a whole. This is also reflected in public perceptions, to the extent that positive attitudes are perceived as the dominant view, which some majority group members may resent. One Anglophone commented 'I don't agree with trying to revitalise something just for the kudos'. One even felt slightly threatened by the resurgence in Guernesiais:

I don't want to get rid of Guernsey French but it's a problem if languages divide people. I would be very upset if English had been marginalised ... if Guernsey French was resurrected one group of people would have special status. (GE28)

\section{Age}

The slightly less positive attitudes in the questionnaire responses from under-18s and students, although not statistically significant, could be seen as worrying for future language planning. However, many of the questionnaires were distributed through workplaces, and the number of respondents aged under-18 was very small and thus the views expressed may not be representative. 
As shown in Figure 2, respondents under 18 were the least likely to agree with the statement 'Speaking Guernsey Norman French is an important part of Guernsey identity' and those over 60 most likely. This difference is statistically significant, with a Pearson regression analysis score of 0.03 . The change in view once respondents reach the age of 18 is notable.

[FIG 2 NEAR HERE]

However, the under-18 age group expressed the most positive attitudes in two areas: firstly, they were most likely to want to know Guernesiais, with $42.9 \%$ agreeing strongly; next came the over-60s (who are also the most likely to know it already), 37.5\% of whom agreed strongly, although this is not statistically significant. Secondly, $28.6 \%$ of under- $18 \mathrm{~s}$ disagreed strongly with the statement 'Guernesiais is irrelevant to the modern world', higher than the average of $16 \%$, while another $21.4 \%$ disagreed mildly. This is just about statistically significant (Pearson $r=0.048)$.

As shown in Figure 3, under-18-year-olds were the age group whose support for teaching Guernesiais in schools was most equivocal, but again not to a statistically significant degree (Pearson $r=0.420$ ). The age group taught in the extra-curricular lessons is under-11s, younger than most questionnaire respondents. Their participation is likely to be decided by their parents, and their own attitudes towards the language are likely to be influenced more by enjoyment of the lesson activities (Nikolov 1999) than by what Gardner and Lambert (1972) call instrumental or integrative orientation, i.e. perceived 'usefulness' of a language, or by perceptions of the speaker community. Teachers in the extra-curricular classes reported that the pupils enjoyed doing something their friends could not. 
[FIG 3 NEAR HERE]

Under-18 is a wide range, which encompasses several stages of development: the attitudes of under-11s and those of teenagers are likely to be quite different. Most of the 11year-olds interviewed thought it would be a good idea to learn Guernesiais in schools ('it's like - we live in Guernsey and - like - we should learn'), although with 13 to 17 -year-olds the proportion dropped to a small minority. Some said they would like to speak it with their grandparents. The 15-16-year-olds expressed the least interest in Guernesiais - only one had even heard of it. The majority of one group of 17-18-year-olds felt that it was not worth learning a dying language not useful elsewhere - but a majority were in favour of introducing Guernesiais at a younger level. Yet all but one of another group of 17-18-year-olds from a girls' school seemed to take it as a matter of course that Guernesiais was worth saving, mainly due to its importance in island heritage.

To make sense of these apparent contradictions, it is possible to generalise that the attitudes of young people towards Guernesiais seem to progress from positive to negative to positive again, reflecting their personal development, as shown in Table 1. This confirms and explains the perhaps contradictory findings of Baker (1992) in Wales and Schjerve (1980) in Sardinia.

\section{[TABLE 1 NEAR HERE]}

Several interviewees noted that it was common for people to reject traditional values in their teens and twenties, but to become enthusiastic about Guernesiais in middle age or later, indeed in several cases this literally involved moving away from the island and then moving back: 
As a teenager I rejected the microcosmic culture that my parents represented - the baby went out with the bathwater ... my rebellion included despising Guernsey French. (GF33)

Another pointed out that the increased self-confidence of mature people helps overcome peer pressure:

Now I'm older I don't feel so intimidated by people saying it sounds odd - it's us, why shouldn't anyone learn it? (QGF39)

It should be stressed, however, that despite peer pressure, age groups are not homogeneous, and that in the questionnaire most differences were not statistically significant. On several occasions two or three generations of a family were interviewed together. In about a third of these 'family focus groups' the younger generation seemed more positive than the older; in another third, vice versa; for the others there was no clear difference in attitudes.

It is often assumed that young people and immigrants will not be interested in Guernesiais, and language maintenance activities may perpetuate this stereotype by focusing on traditional culture. As one interviewee in her 20s stated:

Learning Guernsey French is not cool, there is nothing to encourage the younger generation - the Eisteddfod ${ }^{4}$ is mostly for older people. (GE16)

This indicates that if language planning measures are to attract younger people, they may need to be of a type which interests them. But, as will be seen below, this may not be the priority for organisers of such events. 


\section{Insiders and outsiders}

In the 2001 census, $36 \%$ of the population reported being born outside the island; this was reflected in questionnaire respondents' backgrounds. Of the remaining $64 \%$, a considerable proportion have (mainly British) immigrant backgrounds: there has been a continuous and substantial influx of outsiders since the mid-eighteenth century (Crossan 2007). A commonsense assumption can be made that descendants of immigrants are less likely to speak the indigenous language. A number of respondents felt that people not born in Guernsey were also less likely to be interested in Guernesiais:

It means something to me as a Guernseyman. With less people living in Guernsey with a pure family heritage here it is unlikely to be as important to others. (AQ16)

It's difficult because there's so many English kids and stuff in school now - you know, should we really teach people with no Guernsey background at all Guernsey French because their parents are going to say "well why are they getting taught that?" (AQ123)

However, the attitude questionnaire statistics show no significant overall differences in responses between those born in Guernsey and non-natives. It is worth stressing this, as their presence is often cited as a factor in language decline.

Many incomers are keen to protect Guernsey's distinctiveness, which in many cases is what first attracted them to the island. A few immigrants to both Guernsey and Jersey have learnt the indigenous languages and become influential in language-related activities. One volunteer in an after-school Guernesiais session stated that non-local parents especially had 'warmed to the idea of having something unique and local' (GF23). Another respondent commented: 
It is noticeable that in the last ten years that the uneasy/negative attitudes to the language are being dropped and ironically are not even present in the group of incomers from the UK. (GE13)

It may be that recent immigrants from the UK have been influenced by the promotion of indigenous languages there such as Welsh and Cornish, and are bringing these attitudes with them to Guernsey. An interviewee of Cornish origin commented that she would not wish Guernesiais to go the way of Cornish. ${ }^{5}$

A crucial factor in this apparent majority-population support for a minority language may be that many of the majority population see Guernesiais as part of their heritage too, not only that of the dwindling number of native speakers. As this section has demonstrated, this is even true of respondents who are not of island origin. Although this might seem a positive development in terms of support for language maintenance measures, there are two trends emerging from recent ethnographic observations which indicate that not all 'insiders', especially some of those who see themselves as members of the Guernesiais language community, have embraced 'attitude shift'.

Firstly, old ideologies of Guernesiais as an inferior dialect of French are very strongly ingrained in older islanders, and are reflected in linguistic behaviour. Many still refer to Guernesiais as 'the patois' and think of standard French as the correct, literary form. Convergence towards French has been observed in contexts which might be perceived as formal, including Guernesiais lessons and cultural performances, which together form the mainstay of current voluntary efforts to 'save the language'. Convergence has also been observed in linguistic elicitation or grammaticality judgement sessions, where informants' intuitions of 'correctness' are influenced by a perception of Guernesiais as 'incorrect' and French as 'correct'. 
The covert inferiority of Guernesiais, which contrasts with public rhetoric about heritage and distinctiveness, may also underlie the lack of inclusion of Guernesiais in the school curriculum: even influential figures in the language 'movement' express the view that teaching Guernesiais may adversely affect students' achievement in French, which is deemed to be of greater importance.

Secondly, Guernesiais supporters are split between those who want to expand its domains and open it up to new speakers, and 'traditionalists' or purists whose affective attachment to their heritage language reflects nostalgia for a bygone world. Some of these think of themselves as 'owners' or 'guardians' of the language, and would prefer to retain control of both the language and of language policy (Marquis and Sallabank, in press). This is often expressed as concern about language change, which is perceived as negative:

... they're going to change the language to teach it - it won't be the Guernsey French we know (GF19a).

Such fears are not completely unfounded: in other places where a minority language has gained official support through education, there have been cases of divergence developing between the language of younger speakers who have learnt the 'standard unified' version and older native speakers of 'authentic' varieties: e.g., Scottish Gaelic (Dorian 1981), Quechua (Hornberger and King 1996), Occitan (Paulston 1987), Welsh (Jones 1998), and Basque (Urtéaga 2005). However, to what extent such developments are seen as necessary, (un)desirable, or inevitable is again related to attitudes and ideologies as much as to researchbased arguments. 
In terms of language planning in Guernsey, the result is a lack of strategic direction and of progression in the teaching of Guernesiais, with very few learners attaining post-beginner levels.

\section{Conclusions}

The questionnaire and interview data confirm that stated attitudes towards Guernesiais are largely positive among the majority community (i.e. Anglophones) of both island and external origin, and Guernesiais is generally now seen as a valued element of island heritage. There appears to have been a shift away from the post-World War II monolingual ideal associated with 'modernisation' to recognition of the value of linguistic heritage and bilingualism. Media coverage in recent years almost invariably presents a positive view of Guernesiais: very few people, especially public figures, are now prepared to make on-record statements against the indigenous language (although some express such views privately). The fact that normative pressure makes anti-Guernesiais statements unacceptable illustrates how far attitudes have changed. Language planning measures such as Guernesiais classes at primary schools (which, although not part of the curriculum, require the cooperation of head teachers) and the appointment of a government language officer in 2008 would not have been possible without this attitude shift.

On the face of it, such majority support would appear to bode well for policy-making and language planning. Yet not all traditional speakers have necessarily fully accepted a higher status for Guernesiais - their ideologies and covert attitudes are still influenced by its low status in the traditional diglossic relationship with French, so that they unconsciously perceive Guernesiais as lacking in prestige. In addition, there is an influential sub-group who seem unwilling to 'hand over' control of either the language or language policy to a new generation or to non-native speakers (which amounts effectively to the same thing); this 
echoes the findings of Dauenhauer and Dauenhauer (1998) in Alaska and is discussed further in Marquis and Sallabank (in press).

Language policies exist at all levels of society, including government, institutions, families, and individuals (Spolsky 2004). Like attitudes, they may be overt, covert or naïve (e.g., laissez-faire policies). As observed by Romaine (2002), there are 'weak linkages' between policy and practice/implementation, which may render language planning efforts ineffective. These weak linkages between policy and practice at official and institutional level are paralleled at the personal level by weak linkages between expressed attitudes (which may be seen as overt statements of individual language policy) and language practices at individual and family level. This might help explain the lack of significance of demographic factors (especially language proficiency and origin) in relation to the attitudes found in the survey described above.

Overtly expressed attitudes are not actions: positive attitudes cannot save a language without concrete measures. However, attitude shift can lead to public support and government funding for such measures, and as noted by Romaine (2002) and Spolsky (2004), this may allow speakers of minority languages to claim some public space for their languages and cultures, as in the after-school lessons and festivals mentioned above. Yet while this raises the prestige and linguistic capital of a low-status language such as Guernesiais, it does not ensure its survival, especially as it is neither being learnt in the home nor taught effectively as a second language.

Societal attitudes in Guernsey were influential in the cessation of intergenerational transmission of Guernesiais. Although societal attitudes have changed, it is too late to change practices: the linguistic capacity to re-instate substantial use of Guernesiais in the home has been lost and could only be regained by sustained and effective measures to train fluent adult second-language speakers and young learners, which presupposes that records have been kept 
of the language in use. ${ }^{6}$ If language revitalisation is indeed desired by the majority, the next challenge is to combine the efforts of remaining native speakers, partial, heritage, and nonnative speakers, (potential) learners, voluntary initiatives and government-supported projects into an effective strategy.

\section{Notes}

${ }^{1}$ I would like to thank the many people who helped to circulate language attitude questionnaires, responded to them, and agreed to be interviewed. I thank Clare Ferguson for comments on an earlier draft, and Yan Marquis for valuable insights. This research was funded largely by a UK Economic and Social Research Council doctoral award.

${ }^{2}$ The same proficiency questions were included as in the census to facilitate comparison.

${ }^{3}$ The term 'Guernsey Norman French' was used, following the example of the Census, to avoid ambiguity, but this term is not in common use. This paper uses 'Guernesiais' as the term preferred by the majority of native-speaker respondents, using the currently preferred spelling.

${ }^{4}$ The major annual cultural festival in Guernsey, which includes a 'Guernsey-French' section including poetry and story recitations, short plays, songs, etc.

${ }^{5}$ The last native speakers of traditional Cornish died in the eighteenth or nineteenth centuries, but there has been a remarkably successful revival: see http://www.magakernow.org.uk/ and Ellis (1974).

${ }^{6}$ The author is PI in a project to record remaining fluent speakers, create a language corpus and produce language learning materials.

\section{References}

Annamalai, E. 2004. Public perceptions of language diversity. Paper presented at Dialogue on Language Diversity, Sustainability and Peace (10th Linguapax conference), Barcelona, May 20-23. 
Baker, C. 1992. Attitudes and language. Clevedon: Multilingual Matters.

Cooper, R.L. 1989. Language planning and social change. Cambridge: Cambridge University Press.

Crossan, R.-M. 2007. Guernsey, 1814-1914: Migration and modernisation. Woodbridge: The Boydell Press.

Currie, M., and M.A. Hogg. 1994. Subjective ethnolinguistic vitality. International Journal of the Sociology of Language, 108: 97-115.

Dauenhauer, N.M., and R. Dauenhauer. 1998. Technical, emotional, and ideological issues in reversing language shift: Examples from Southeast Alaska. In Endangered languages: Language loss and community response, ed. L.A. Grenoble and L.J. Whaley, 57-98. Cambridge: Cambridge University Press.

de Bres, J. 2011. Promoting the Māori language to non-Māori: Evaluating the New Zealand government's approach. Language Policy 10: 361-376.

Domaille, D.R.F. 1996. Analyse sociolinguistique du Guernesiais. Unpublished MA Dissertation, University of Bristol.

Dorian, N.C. 1981. Language death: The life cycle of a Scottish Gaelic dialect. Philadelphia: University of Pennsylvania Press.

Dorian, N.C. 1993. A response to Ladefoged's other view of endangered languages. Language 69: 575-579.

Ellis, P.B. 1974. The Cornish language and its literature. London: Routledge and Kegan Paul.

Edwards, J.R. 1977. Students' reactions to Irish regional accents. [Jul-Sep]. Language \& Speech 20: 280-286. 
Edwards, V., and L.P. Newcombe. 2005. When school is not enough: New initiatives in intergenerational language transmission in Wales. International Journal of Bilingual education \& Bilingualism 8: 298-312.

Fennell, D. 1981. Can a shrinking linguistic minority be saved? Lessons from the Irish experience. In Minority Languages Today: A Selection from the Papers Read at the First Conference on Minority Languages at Glasgow University 8-3 September 1980, ed. E. Haugen, J.D. McClure and D. Thompson, 32-39. Edinburgh: Edinburgh University Press.

Ferguson, C.F. 1959. Diglossia. Word 15, 325-340.

Fishbein, M., and I. Ajzen. 1975. Belief, attitude, intention and behaviour; An introduction to theory and research. Reading, MA: Addison-Wesley.

Gallienne, W.T. 2004. The importance of our language. Review of the Guernsey Society 60: 24-26.

Gardner, R.C., and W.E. Lambert. 1972. Attitudes and motivation in second-language learning. Rowley, MA: Newbury House.

Garrett, P., N. Coupland, and A. Williams. 2003. Investigating language attitudes: Social meanings of dialect, ethnicity and performance. Cardiff: University of Wales Press.

Giles, H., ed. 1977. Language, ethnicity and intergroup relations. European Monographs in Social Psychology. London: Academic Press.

Grenoble, L.A., and L.J. Whaley. 2006. Saving languages: An introduction to language revitalization. Cambridge: Cambridge University Press.

Hoare, R., and A. Coveney. 2000. The linguistic marking of identity among young people in Brittany. Revue-Parole 14: 93-125. 
Hornberger, N.H., and K. King. 1996. Language revitalization in the Andes: can the schools reverse language shift? Journal of Multilingual and Multicultural Development 17: 427-441.

Jaffe, A. 1999. Locating power: Corsican translators and their critics. In Language ideological debates, ed. J. Blommaert, 39-66. Berlin: Mouton de Gruyter.

Jones, M.C. 1998. Language obsolescence and revitalization. Oxford: Oxford University Press.

Jones, M.C. 2001. Jersey Norman French: A linguistic study of an obsolescent dialect. Oxford: Blackwell.

Low, G. 1999. What respondents do with questionnaires: Accounting for incongruity and fluidity. Applied Linguistics 20: 503-533.

Marquis, Y., and J. Sallabank. In press. Speakers and language revitalisation: A case study of Guernesiais (Guernsey). In Language endangerment: Documentation, pedagogy, and revitalization, ed. M. Jones and S. Ogilvie. Cambridge: Cambridge University Press. May, S. 2006. Contesting minority language rights: Addressing the attitudes of majority language speakers. Plenary. Sociolinguistics Symposium 16, Limerick, Ireland, 6-8 July.

Milroy, L. 1987. Language and social networks. Oxford: Blackwell.

Nikolov, M. 1999. "Why do you learn English?" "Because the teacher is short." A study of Hungarian children's foreign language learning motivation. Language Teaching Research 3: 33-56.

Paulston, C.B. 1987. Catalan and Occitan: Comparative test cases for a theory of language maintenance and shift. International Journal of the Sociology of Language 63: 31-62.

Potter, J., and M. Wetherell. 1987. Discourse and social psychology: Beyond attitudes and behaviour. London: Sage. 
Price, G., ed. 1984. The languages of Britain. London: Edward Arnold.

Priestly, T. 1989. "Our dialect sounds stupid": The importance of attitudes to so-called substandard languages codes as a factor in the (non-)retention of Slovene in Carinthia, Austria. In Fourth International Conference on Minority Languages, Vol. II: Western and Eastern European Papers, ed. D. Gorter, J. F. Hoekstra, L. G. Jansma, and J. Ytsma. Clevedon, Multilingual Matters.

Romaine, S. 2002. The impact of language policy on endangered languages. International Journal on Multicultural Societies 4: 194-212.

Ryan, E.B. 1979. Why do low-prestige language varieties persist? In Language and Social Psychology, ed. H. Giles and R. N. St. Clair, 145-157. Oxford: Blackwell

Schjerve, R.R. 1980. Bilingualism and language shift in Sardinia. In Minority Languages Today: A Selection from the Papers Read at the First Conference on Minority Languages, Glasgow University. Edinburgh University Press.

Spence, N.C.W. 1993. A brief history of Jèrriais. Jersey: Le Don Balleine.

Spolsky, B. 2004. Language policy. Cambridge: Cambridge University Press.

States of Guernsey. 2002. 2001 Guernsey census: Report on the census of population and households. Guernsey: States of Guernsey Advisory and Finance Committee.

Urtéaga, E. 2005. La langue basque au début du XXIe siècle [The Basque language in the early 21st century]. Marges Linguistiques 10: 175-189.

Williamson, R.C. 1991. Minority languages and bilingualism: Case studies in maintenance and shift. Norwood, NJ: Ablex.

Youngman, M.B. 1978. Designing and analysing questionnaires: Rediguides 12.

Nottingham: University of Nottingham School of Education. 